Metal-Catalyzed Asymmetric

Synthesis and

Stereoselective

Reactions

\section{Key Words}

asymmetric

catalysis

ketones

protonation

silver

silyl enolates

A. YANAGISAWA, * T. TOUGE, T. ARAI (CHIBA UNIVERSITY, JAPAN)

Enantioselective Protonation of Silyl Enolates Catalyzed by a Binap.AgF Complex

Angew. Chem. Int. Ed. 2005, 44, 1546-1548.

\title{
Enantioselective Protonation of Silyl Enolates Catalyzed by a Binap-AgF Complex
}

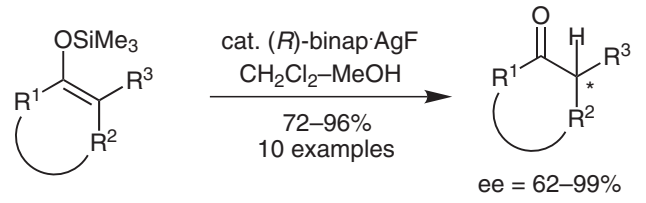

Significance: A catalytic enantioselective protonation of trimethylsilyl enol ethers using AgF-binap under very mild conditions $\left(\mathrm{CH}_{2} \mathrm{Cl}_{2}-\mathrm{MeOH}\right.$, $-20{ }^{\circ} \mathrm{C}$ to $0^{\circ} \mathrm{C}$ ) is reported. Generally good to excellent yields and ee's were obtained. This method allows for preparation of enantiomerically enriched $\alpha$-chiral ketones from racemic ketones by silyl enol ether formation followed by enantioselective protonation.
Comments: Cyclic trimethylsilyl enol ethers gave generally good yields and ee's using methanol as the proton source.

In the cases when $\mathrm{R}^{3}=$ aryl, excellent yields and up to $99 \%$ ee's were obtained. Both 6- and 7 membered ring systems work well. However, no acyclic silyl enol ethers were reported in this communication. It was rationalized that $\mathrm{Ag}(\mathrm{l})$ acts as a Lewis acid to activate $\mathrm{MeOH}$ and $\mathrm{F}^{-}$interacts with the silyl group in the protonation process. Previously, Yamamoto has reported that a chiral Lewis acid $\mathrm{SnCl}_{4} / \mathrm{BINOL}$-catalyzed enantioselective protonation of silyl enol ethers and ketene disilyl acetals using 2,6-dimethylphenol as the proton source (S. Nakamura, M. Kaneeda, K. Ishihara, H. Yamamoto J. Am. Chem. Soc. 2000, 122, 81208130). Nakai has reported cationic Pd(II)/BINAP systems to achieve the same reactions using $\mathrm{H}_{2} \mathrm{O}$ as the proton source (M. Sugiura, T. Nakai Angew. Chem. Int. Ed. 1997, 36, 2366-2368). 